\title{
THE ADAPTATION OF AUDITING TO NEW TECHNIQUES
}

\author{
door Prof. A. B. Frielink
}

\section{INTRODUCTORY}

Since the beginning of the 1950s, when electronic digital computers were put to work in the business data processing area, accountants in general, and auditors in particular, have been well aware that this new development would have a considerable impact on the ways in which the auditor must arrive at his opinion on the soundness of financial statements. This awareness has been made clear in a relatively large number of publications.

In 1961 the publications available were reviewed in a small booklet [1]. Apart from 4 forerunners dealing with mechanized systems, the bibliography at that time listed 66 items, nearly all of them articles and short brochures. The firstlisted publication (chronologically) dealing with electronic data processing was by Joseph Pelej [2] and dated July, 1954, i.e. some two years after the first experiments started.

Since 1961, many more papers and a few books dedicated to the subject have appeared. In the present paper no attempt is made to construct a new bibliography, primarily because the ideas and practices set forth in the more recent papers only restate (often, it is true, more succinctly and more practicably) the ideas that were already contained in the older literature. Attention, however, is drawn to some recent publications which present a systematic approach, both theoretical and practical, which is of paramount importance to every practising auditor who is confronted with Automatic Data Processing (A.D.P.).

These are: the book by Wayne S. Boutell [3], the book by J. W. van Belkum \& A. J. van 't Klooster [4] (to be translated into English) and the Computer Research Studies [5], prepared by the System Development Corporation for the American Institute of C.P.A.'s.

It was felt that no useful purpose could be served by trying in this paper to summarize again what had already been summarized very adequately in the books just mentioned. On the other hand, it is felt that the general approach of all, or at least the large majority, of the literature available a this moment stresses only one aspect of A.D.P.'s impact on auditing. This aspect may be described as the implementional one; the problem posed is: in what ways does the type of equipment used for the preparation of financial statements affect the auditor's task?

In the opinion of this author there is at least one other aspect that is as important, or even more important. This aspect is related to the management techniques applied in controlling an organizational entity which are becoming feasible through the use of modern equipment. This latter aspect may be called the functional aspect.

The primary function of modern accounting could be described as: to offer management a means of controlling the entity (comprising controlling both dayto-day activities and non-recurring decisions); the secondary function is: to enable management to justify themselves to those who have given them their mandate. It is, in general, efficient and customary to integrate both these functions into one system of accounting. This implies that any change in management techniques 
has some bearing - quite apart from its implementation - on the second function of accounting as well, and this second function is the one in which the auditor is most interested when he is to form an opinion on the soundness of financial statements.

I am of the view that in the not far-distant future auditors will experience a more severe impact from new management techniques than from data processing techniques as such.

For this reason the attempt is made in the paper that follows to stress the functional aspect of the influence of A.D.P.

\section{THE MAIN FEATURES OF AUTOMATIC DATA PROCESSING AF- FECTING AUDITING}

\subsection{General}

Every author known to me holds that the technical equipment used in preparing financial statements can influence neither the aims of an auditor nor the principles according to which these statements are subjected to an audit. This implies that it is only the methods by which an auditor arrives at his opinion that can differ under different technical circumstances.

This author mainly agrees with this view, but he feels that public confidence in what should be expected from a well-qualified auditor gradually evolves to a more advanced state, and that auditors must see that they keep abreast of this evolution rather than try to hold back the clock. It seems undeniable that what constituted the aims and purposes, as well as the basic principles, of auditing for what has already been a relatively long time is still valid and will continue to be so in the future. This, however, does not exclude the possibility that the availibility of new technical equipment may enlarge the scope of what is expected from an auditor and reach into realms which at one time were hardly to be thought of.

Let us look at this question from a somewhat unorthodox angle. Financial statements are an important means of communicating financial information. In order to be in a position to report that financial statements give a fair view of whatever aspect is selected, the auditor will have to know:

- what information, selected from the vast mass of data available, is, and what is not, relevant to the particular purpose to be served;

- whether the basic data are complete and correct, and whether the processing of the data leading to useful information has been done correctly.

The relevancy of information depends not only on the purposes that are to be served by it but also on the cost of obtaining it. If additional information can be provided without much trouble - which means inexpensively - such information might be considered relevant, while the idea of providing such additional information might have to be abandoned if the cost of the data processing were high. Thus, new technical equipment which makes it possible to provide additonal information at extremely low cost may cause a shift in the scope and contents of financial statements.

Consequently, when determining the relevancy of information to be contained in a financial statement, the auditor must be in a position to estimate at what cost 
various types of information can be acquired. One of the auditor's important fields of knowledge could be said to be specialized information science ${ }^{1}$ ).

To put it another way: to be qualified for the job, an auditor must be master of a specialized knowledge of business information.

If that is so, it seems logical that public confidence in an auditor should relate not only to his first-mentioned field of knowledge (the question whether data and processing are complete and correct) but also to this evaluation of whether everything relevant has been brought forward in the information provided.

Financial statements are brought not only before the general public, but - in various detail and form - also before boards and managers of all levels. Being convinced of the auditor's specialized knowledge of business information (and, of course, his independence), the general public could reasonably expect the auditor to apply this knowledge to convince management that all relevant information (i.c. information that is useful, taking into account its cost) must be used. Possibly, this might involve qualification or even refusal of a certificate in cases where management ignores important items of relevant information, even though the published financial statements are correct. Looked at from a different view-point: inadequate use of relevant information involves a company in a risk which is comparable to inadequate fire-insurance. Both inadequacies endanger the future prosperity of the company, without this fact being disclosed in the conventional published annual accounts.

Certainly, this view of the auditor's responsibilities is not yet generally held. It seems likely, however, that the very rapid introduction of new sophisticated information systems, will, within a relatively short time, induce investors and the public in general to require some confirmation that the company's information system is adequate. If, by that time, we, as auditors, are not prepared to give an independent opinion on this aspect of financial reporting, undoubtedly some other group will be called upon for this purpose.

\subsection{Features related to the way in which data is recorded, processed and presented}

Contrary to conventional accountancy, A.D.P.-data is almost or completely illegible to the human eye and is easily erasable without trace; processing happens inside a "black box", the intricacy of whose construction one can only imagine and whose speed of working one cannot envisage. Presentation, by the use of display screens and audio devices, of information derived from data which is in course of being processed is rapidly becoming a volatile process.

Technically it is possible to produce all permanent records by computer in nearly the same format in which these records were conventionally produced in manual or less-sophisticated mechanical systems.

The fact that this is often done - until now - stems partly from management's hesitancy to abandon existing safeguards before being fully convinced of the $\therefore$ liability of the new system under all imaginable, even extreme conditions; it is induced partly by government regulations, and partly to comply with the wishes expressed by auditors. It is clear, however, that this solution of a problem of

1) It should be noted that this implies something quite different from "information theory" [6], which deals with the non-semantic aspects of information and should better be termed: "statistical signal theory" [7]. 
illegibility and volatility is normally very expensive. Consequently, when management gradually gains confidence in the new system it will try to cut out everything that is not clearly necessary within that system. Eventually government agencies, too, will become convinced that large parts of what they deemed necessary can be cut out. If, at that stage, auditors still insist upon a relatively high cost being incurred for the sole purpose of making the information processing system capable of being audited they can expect very strong opposition and not unreasonably.

Therefore, ways and means should be developed to counteract the impeding effects on auditing of illegible and volatile records.

Even while this final stage has not yet been reached auditors already experience a difficulty in their field work which stems from the differences between nonautomatic and automatic data processing. This difficulty can be traced back to the differences in sequence which various types of processing require.

The sequence in which items processed automatically are available of ten differs fundamentally from that in which items should be available for manual processing. As long as auditing is fully or mainly a manual operation on data, this difference in sequential order often offers a material obstacle to efficient auditing. Again, it is technically possible to (re)sort all items so as to enable the auditing procedure to be carried out in the long-established, conventional manner, but, again, this might be very expensive. Several other means have been developed to provide a so-called audit trail. Many of these means are, however, applicable only to particular types of operation, most of which are becoming outdated.

The general inference to be derived from this development is the urge to turn those parts of auditing which lend themselves to it from a manual into an automatic process. We shall go into this in section 3.

\subsection{Organizational implications}

In the majority of cases auditing depends largely on effective internal control, which in itself implies the co-operation of two or more employees within an organization. The methods by which this co-operation is established have been evolved from relatively long experience.

Only to a very small extent have these methods been based on a fundamental analysis (the independence required between the operating, the accounting, and the custodian departments [8]; mostly they are pragmatically determined in relation to a particular type of organization [9]. Of course, there is nothing wrong in such a pragmatic approach, but its consequence is that a radical change of circumstances brings the need for a complete re-thinking or a trial-and-error mode of finding new solutions.

This, it appears, is the case with the introduction of automatic data processing, which results in a radical change which makes obsolete a number of well-established internal control measures, while, on the other hand, it makes available types of internal control which were not previously applicable.

One might try to list the ways in which automatic data processing can weaken internal control and can strengthen it. This has already been done several times (compare [1] section 3, in which 5 factors which can weaken and 6 factors which

m a b blz. 35 
can strengthen internal control are summarized), and no new factors can be added here. However, recent developments give the general impression that two factors are becoming of paramount importance:

1 The weakening factor of bringing all the information and recording under the control of one individual (the operator) is gaining importance through the new feature that any one employee of an organization, through the use of remote terminals (input and enquiry stations) can control information and recordings, so that undue power is given not only to the few specialized computer-operators, but also to many employees of various status. New methods have to be developed automatically to safeguard information from undue interference ${ }^{2}$ ).

2 On the other hand the strengthening factor of improvement of reporting, resulting in weak areas in the organization being spotted earlier and with more accuracy, is gaining importance through immediate processing and the use of remote enquiry stations by higher management. An effective use of this factor, however, requires a very thorough analysis of all operations which are geared through the automatic information system. For the independent auditor this factor has its weakening effects too, because undue interference by top management becomes easier if no subaltern personnel have to be involved in operations, including cash transactions.

Generally, modern computerized organizations tend to make routine-accounting personnel redundant, so that only the operating and the custodian departments remain as segregated functions, and even some of the custodian tasks will be handed over to the automatic information system (e.g. the "custody" over accounts receivable). The influence of this tendency on internal control is tremendous; it can only be counteracted by charging the automatic information system with the task of exercising internal control, of refusing unauthorized input data, and of reporting doubtful transactions directly to the appropriate agencies (including the external auditor in some cases).

\subsection{Features related to the way in which management controls the organization and reaches decisions}

Automatic data processing enables the management to exert a much stricter control over an organization than is possible by other means. Efficient applications make it feasible to link up each recorded transaction (or group of transactions) with much other data available within the system. This can be seen as a continuous test of consistency of (almost) everything within the information system. This test is not based on vague feelings or personal opinions, but on calculations and statistical analysis.

An automatic data processing system cannot be taught in one or more large steps to do everything that has been learned in an organization. Tedious effort is necessary to bring the system up to a certain level. But then, unlike people, computers do not forget or unlearn what they have been taught. Further, it is not possible for

2) One large organization in the Nederlands, experimenting with remote-control data processing through the public telephone service, recently received a telegram from another large firm: "Thank you for twentyseven minutes of computing time stop used your computer through dialling 224466-09". It appeared that an employee who knew about the connection had changed employer!

$\mathrm{m} \mathrm{ab}$ blz. 36 
computers to learn on their own to adapt themselves to changing circumstances. Accordingly the process of building up the information system is one which can never be finally completed.

These two restraining factors necessitate a continuous feedback from management to the systems development department in the organization.

Whether this feedback will improve the system's qualities or jeopardize its functioning as an implement of internal control largely depends on the capabilities and the motivation of management, and the capabilities of the systems development department. In other words: a capable and well-intentioned management can, through an automatic information system, very greatly tighten their control of the organization; a less capable or ill-intentioned management can jeopardize both its own control and internal control in general.

The taking of decisions often includes 3 steps (with regard to information):

- determining the present position;

- analysis of past experience to determine the rules (or laws) that govern the response of a system (or subsystem) to certain types of decisions;

- evaluating the probable responses to a number of possible alternative decisions.

In all three steps, automatic information processing can support management (through real time, or up-to-the-minute processing; analysis; simulation and optimization). Internal control can benefit from these computer aids in the same way (but to a much larger extent) as it has benefited from standard cost systems. If, for any decision of some importance, the three steps have been followed, everything relevant has been recorded, and the outcome has been compared to the anticipation, nothing much unexpected can happen without the system analysing the causes, which might include fraudulent interference.

It is evident that a long time will elapse before the highly sophisticated control and decision systems sketched here will embrace many large organizations. But it is not necessary to wait for all-embracing systems; efficient use of these features for parts of an organization or for particular areas of activities is definitely feasible at present. Auditors should keep in mind the possibilities and be well aware of their consequences for internal control.

\section{SUMMARY OF IMPLEMENTIONAL INFLUENCES OF AUTOMATIC DATA PROCESSING ON AUDITING, AND SOLUTIONS PROPOSED}

Whenever in the normal course of an assignment an auditor experiences the need to check one or more entries to an account, he usually proceeds in one of two ways: either he starts from the source document, builds through the books of prime entry to the account, or else he starts from the account entry and works down through the books of prime entry to the source document. This is usual, simply because manual bookkeeping is efficiently organized to make it possible.

With automatic data processing the concept of an ,account" still holds good, but its outward appearance differs fundamentally from a manually posted account, and books of prime entry are not kept. In fact, automatic data processing is much more straightforward than any of the older accounting systems: the machine deals directly with the basic data according to a program (including add- 
ing to or substracting from the appropriate accounts), if these data are made available to the machine in some form it can read (or scan, or sense). Compare this to the round-about-way of manual bookkeeping: summarize a number of basic documents of one type; post the sum total in some register; foot the register for a certain period of time; transfer the register totals to a journal; post from the journal into the general (or some specific) ledger; through adding and substracting establish the balance of each account in the ledger. Remember that many types of machine-accounting, which in itself do not follow the same round-about-way, still make use of predetermined totals, journals (in the form of proof-sheets or cash-register tally rolls) and periodical balancing. Evidently, the reason for this is that with each step of machine-accounting so much manual labour is involved that the error probability is relatively high. Without the use of these types of proving, some errors will never be detected, others will only be detected in balancing operations at the end of a period, when their location will involve a lot of work; still others will only be detected by some outside agency (an employee finding a shortage in his pay; a customer finding an invoice or statement of account rendered too high). The latter findings will obviously be to the detriment of the organization's goodwill.

With A.D.P. the same types of proving recordings are technically possible. And several of them have been proposed to ensure adequate internal control:

- Batching or grouping source documents in order to establish input control.

- Independent control groups to prelist input data and compare output with predetermined totals.

- Automatic loggers, recording all operations with particulars of operator's interferences (comparable to proof-sheets).

Various other, more specific measures have been proposed to ensure adequate internal control:

- Introduction of a segregation of duties, e.g.:

- control over inpur;

- control over and analysis of output;

- control over operations;

- systems analysis;

- programming;

- physical control over operational programs.

- Introduction of programmed accuracy checks and programmed plausibility checks.

- Strict rules for error correcting, charging two or more people with this task.

- The requirement that at least two programmers co-operate in programming and in particular in alterations to programs.

It will be clear from this short summary of measures found in literature and practice that the discriminating judgment of a qualified specialist is needed to choose, in any particular case, appropriate internal control measures such as will assure effective internal control and not be prohibitively expensive. It might be less self-evident that most of the measures discussed are hardly applicable in information systems where all managers and many employees have direct access to the computer installation through remote controls. We shall come to this type of application in section 7. 
Even if an adequate system of internal control has been set up and installed - and let it be assumed that the auditor has satisfied himself about that - the auditor will have to test that system in order to ascertain that it is in fact operating in the prescribed manner or that the deviations therefrom are immaterial (ref. [3], page 54). It is here that most authors see the greatest difficulties for the auditor. Many of them require that some form of audit trail should be provided, so that the auditor can do his test-checking more or less in the same way as with manual systems.

Others contend that stress should be laid on the audit of the computer programs (by the use of test decks) or on the correctness of output (by the use of an independent computer-auditprogram for re-processing parts of input data under the control of the auditor). Only a few authors argue in favour of a system of auditing „by exception" (using the computer installation to recognize and signal the „exceptions" to be audited).

It seems undeniable that further development of efficient use of A.D.P. systems tends to force the auditor to adopt auditing "through" or even „with" the computer. This approach is described by Bourell [3], who gives some examples of computer audit programs.

\section{APERÇU OF MANAGEMENT TECHNIQUES PARTLY OR WHOLLY BECOMING FEASIBLE THROUGH THE USE OF A.D.P.}

It is not intended to deal here exhaustively with these new management techniques. An extensive literature already exists on the subject and new applications are continually described in journals. Some books which seem useful to auditors are listed in references [10] to [14].

The management techniques under consideration can be categorized as follows:

1 Decision models based on hypothetical situations. Typical example: management games. Models of this type, which in their response come somewhat near actual situations, can only be adequately handled by computer.

2 Decision models for operational use in actual circumstances. Typical example: inventory control optimization programs, process control in e.g. the petro-chemical industry. Only by computer can the necessary complex calculations be made in time.

3 Simulation techniques. On the basis of an analysis of response to actual decisions in the past, a model is set up to simulate the behaviour of a (sub-)system; the response of the (sub-)system to various inputs is studied, which study will, eventually, lead to a (near-)optimum decision. Typical examples are: programs to optimize the product mix of chemical works under various price and demand conditions; programs to calculate the most efficient location for building a new factory; programs to study the response of a system to variations in pricing policy under various suppositions. Because actual problems always involve a relatively large number of factors, of ten interrelated, only very fast calculation techniques can adequately handle these problems.

4 Planning and scheduling techniques, which may make use of decision models, simulation techniques and critical path methods. Typical example: project plan- 
ning using $\mathrm{PERT}^{3}$ ), $\mathrm{CPM}^{4}$ ) or other network techniques. Here, too, the many factors involved indicate the use of computers for practical problems.

5 Man-computer systems, in which the computer part makes use of one or more of the above-mentioned techniques. The man uses his faculties of taking the initiative, of deciding on questions which cannot be decided upon by calculation, and of bringing in ,common sense". Typical examples, up to now, are mostly outside the business sphere: air-traffic control systems; space-flight control systems. A few business examples have been mentioned in literature, but are not described in detail: banking, hospitals.

It is striking that the so-called operational research (O.R.) techniques, which could, perhaps, be better termed optimization techniques, after having proved their usefulness in world war II, are today being used by business firms only to a very small extent. Such a use is not meant to suggest that O.R. or computers should „take over" business. Even in the - very few - cases where all or many decisions can be programmed, adaptation of the program to changing circumstances is a man's job. In the large majority of cases all that O.R. and the computer can do is to give very useful help to the decision-making human being. This help should be utilized to achieve better results and to avoid a number of the mistakes inherent in unaided human decision-making, but if, and only if - and this should be studied in each particular case - the promise of better decisions is of greater value than the estimated cost of applying these techniques.

Auditors should, in each of their assignments, form an opinion on the possibility of a net positive result from the application of these techniques.

It should be borne in mind that an isolated approach will not lead to a definite answer with regard to that possibility. This is so, because the data to be collected for the purposes of these techniques are for a large part the same data to be collected for accounting purposes in the more conventional sense. Separate collection and processing leads to inefficiencies which of ten prohibit (through the extra cost incurred) the application of the new techniques. In many cases only integration of the various aims for which data are assembled can lead to efficient applications.

There seems to be one major reason for the fact that the new techniques have only penetrated to a small extent into business. That is the necessity to think far in advance. Businessmen, in general, are in the habit of reasoning thus: if $\mathrm{E}_{1}$ (event 1), then we shall do $A_{1}$ (action 1), if not, we will think again. Adequate use of decision models, simulation and O.R.-techniques, planning and scheduling techniques requires an advanced mode of reasoning: if $E_{1}$, then we shall do $A_{1}$; if not we shall analyse $E_{2}$, then $A_{2}$; if not, perhaps $E_{3}$, then $A_{3}$; if $E_{3}$ plus $F$, but not $G$, then $A_{4}$; etc. until only ultimately is the stage of ,we will think again" reached.

This necessity to think out in advance a number of more or less likely combinations of facts, however, also exists in any computer application, no matter how unsophisticated that may be. This, in fact, is another link between A.D.P. and the new management techniques.

A separate category of management techniques relates to personnel management. It seems that Taylor's ideas, which were very useful for the technology

3) Program Evaluation and Review Technique.

6) Critical Path Method.

m a b blz. 40 
existing at his time, are hardly applicable any longer to automated systems. It is felt that these problems are fully outside the auditor's (or the accountant's) scope, but he has to know that they exist and, if need be, draw management's attention to them.

\section{INTEGRATION OF INFORMATION FOR MANAGEMENT AND FINANCIAL STATEMENTS FOR PUBLICATION; TOTAL SYSTEMS}

It should be clear that the purposes of the information to be provided to management on the one hand and to the public on the other are so widely divergent that the two in their final form are hardly recognizable as pertaining to the same business.

Management information is produced to enable management to steer the organization. For this purpose the question whether the steering in the past has been successful is only of incidental value. Much more pertinent is an answer to the question of what steering measures should be taken now and in the near future to make the steering successful. Its purpose is "prospective”.

Public information is produced to enable shareholders, and others who have an interest in the business, to decide to what extent the management has been successful in the past. Its purpose is ,,retrospective”.

Still, it would be one-sided to see only the retrospective aspect of public information. Possible future shareholders, potential customers and suppliers, potential lenders, staff, are, as a matter of course, interested in the future prosperity of the business. That is one reason why public information about a business should distinguish between operational profits (of which continuity is presumed unless otherwise indicated) and incidental profits and losses.

Even keeping this in mind, the difference between management and public information is great, due to the fact that management do, and the public do not, have the power to influence future success by taking steering measures.

Why then should there be thought of integration of both types of information? The main reason seems to be that both derive their basic data ${ }^{5}$ ) from the same sources. Integrated processing of these basic data is generally more efficient than segregated processing, because:

- input into the processing equipment is one of the most expensive parts of automatic data processing; any subsequent input of the same, or nearly the same, data should be avoided as far as feasible;

- only through intricate and expensive measures can segregated processing assure inherent concurrence between the two or more ways of processing;

- segregation leads to divergences in both terminology and the boundaries between concepts, so that unhealthy misunderstandings occur (in many enterprises, for example, the planning department has quite a different opinion on what constitutes a "sale" or a „pending-order" than the accounting department).

Generally, integration of management and public information processing cannot be reached in one step. In most cases only some of the aspects of management

5) Information and Data are used here in the sense of the vocabulary of ref [15]. 
information can be integrated with public information. The general tendency with A.D.P., however, seems to be that gradually all aspects of management information can be integrated into one system; it is then efficient not to leave out the public information aspects.

If and when all aspects of the information system have been integrated and, through feed back channels, been connected or integrated with the operating systems of an organization, a "total system" has been achieved [16]. Often authors do not recognize that, within any system except the hardly relevant very simple (sub-)systems, human beings play an essential part; they explicitly state, or imply, that a total system can only exist if on all levels the same extent of automation is reached. This use of the term is not meant here. The term total system here should be understood as a fully integrated information and operating system, where machines (including computers) do the tasks they are most suited for, and men (in close co-operation with the machines) fulfil the tasks which are less suited for machines.

Just to make this concept as clear as possible, a rough outline of a total system for an arbitrary manufacturing enterprise is given:

Continuously things happen: a potential customer asks for a price quotation; an order is received; a customer's cheque is received; a department or a particular machine starts production on a specific order; the production of a work order is finished; goods are received from suppliers; a worker is reported ill; a machine is out of order; a price quotation for raw material is received; the sales-manager wants a new product with which competing firms are successful; etc.

Factual information about all these events is fed into the computer installation at the moment it arrives. Some types of information are received in machinereadable form (e.g. MCR-cheques; production reports in punched card form or as a series of electrical impulses generated by the production machines). Other information requires human interference to be converted into machine readable form (e.g. punching of cards or tape) with the indispensable verification of manual operations.

\section{The computer installation:}

- processes the information in the sequence it is input (that is the sequence in which it is created);

- decides what has to be done next; i.e. evaluates the processed information;

- does itself immediately everything for which sufficient information is available and for which it has output-units (e.g. prints invoices and shipping orders; prints cheques to pay suppliers; prints reminders for customers);

- instructs the staff involved to take corrective measures if sufficient information is available to come to a definite conclusion (e.g. worker A, who is reported ill, should be replaced by $B$, whose place should be taken by $C$, etc. to worker $Q$ whose job should be postponed; the service department should send mechanic $R$ to the machine which is out of order, after he has finished the job on which he is busy now);

- requests from the employees involved additional information necessary for a definite conclusion (e.g. what is the estimated time mechanic $\mathrm{R}$ will need for the job on which he is busy now?);

- informs the staff involved about the state of affairs, together with all relevant

$\mathrm{m}$ a b blz. 42 
details (but without any detail that is of no concern), if the information available within the computer is insufficient to reach a conclusion (e.g.: to order a particular type of raw material from a firm which only the purchasing department knows has surplus stocks which might be purchased at a low price);

- calculates and reports upon request the consequences of measures considered by management, in so far these are foreseeable on the basis of available information; - informs top management, and if need be the independent auditor, of the overall state of affairs and of all decisions taken by lower management which are unusual or exceed certain limits;

- prepares drafts of monthly, quarterly, and/or annual reports for publication.

\section{THE FUNCTION OF THE PUBLIC ACCOUNTANT}

\subsection{In general}

Before going into the consequences of total systems for the auditor, it seems advisable to summarize the function of the public accountant.

Montgomery [17] lists 5 types of services performed by certified public accountants:

- examination of financial statements;

- tax services;

- management services;

- other services to clients;

- public services.

Part of these services mainly have auditing aspects (examination of financial statements and some of the ,other services"); the others are of an advisory character.

In most cases a sharp distinction is made between ,,management services” and the other services. The editors of Montgomery's [18] even imply that management services could only be rendered by public accountants who specialize in them. But, if what these authors wrote 10 years ago - "the time is ripe for a general overhaul of accounting and clerical operations and routines" - is true - and it appears to be so - auditing requires the auditor to master large parts of what is usually reckoned to belong to management services.

The examination of financial statements (internal or external) can only lead to an adequately formed opinion if the accounting procedures and techniques on which they are based are efficacious and efficiently applied, taking into account the state of the art at the particular time. According to this view, the auditor should not restrict himself to accepting the accounting system in use at its facevalue, but in all auditing engagements he should form and express an opinion on the overall efficiency of the accounting system as both a tool for management and a basis for the production of external financial statements which give a fair presentation of the state of the affairs.

Consequently, some sort of integration is necessary between auditing and management services dealing with the information system. 


\subsection{Auditing}

Auditing, as the most characteristic of the services performed by public accountants, requires a full understanding of the way information is and should be used in managing an organization. In addition, auditing of external financial statements requires that the auditor be fully independent.

One of the important auditing aspects of information systems is the concept of internal control (in its wide sense as described in General principles of auditing, section 10; quoted in ref. [10].

Studying the internal control system, advising management about weaknesses and practicable ways in which these can be eliminated, belong to auditing, and not to the category of management services.

As formulated in ref. [19], ,internal control" embraces: „the whole system of controls, financial and otherwise, established by the management in order to carry on the business of the company in an orderly manner, safeguard its assets and secure as far as possible the accuracy and reliability of its records".

It does not need much reasoning to deduce from this the conclusion that neglect of the use of information which is, or might be useful, and which can be obtained at a price which is reasonable in the light of its possible usefulness, constitutes a weakness in the internal control system. A weakness which should be analysed by the auditor, about which he should inform the management, and for which he should, at least, point the way for improvement.

\subsection{Advisory}

From the foregoing section it should be clear that to give advice is inherent - at any rate a sequel - to auditing. That is why the advisory function of the public accountant cannot be separated from the auditing function. In some cases the auditor's ,advice" cannot be more than a general remark of the type ,insufficient attention is given to the problem of $\mathrm{A}$; the management is advised to look into that area and - perhaps - consult an expert of category P". In other cases the auditor can and should go somewhat further. In the problem fields in which he is - or is righly expected to be - an expert, he should prepare the desirable measures himself.

It is contended here that auditors should be experts in business information systems and be capable of working out elaborate plans for the improvement of such systems, including the application of A.D.P., mathematical techniques and simulation.

It might be argued in reply that no one man can master auditing and these relatively new techniques sufficiently to call himself an expert in all of them. There is, however, no need for this, since the profession to a great extent is organized in small to very large partnerships. Between them the partners should be able to master the knowledge necessary to bring the firm up to the level of „expert in information systems".

The small firm and the sole practitioner should make arrangements for taking counsel from specialized colleagues wherever the need arises.

Of course, other advisory services can be adequately performed by specialized public accountants or specialized departments of public accounting firms. As they do not deal with the information system, these services are not discussed here. 
Total systems are to be understood in the sense indicated by the example given at the end of section 5. A total system should not be interpreted as a fully automatic system. Fundamental in the concept as it is treated here is the interconnection of men and machines, each charged with the tasks for which they are most suited [20].

\subsection{The need for auditing}

It might be doubted whether a "total system" requires any auditing. The answer is affirmative for two reasons:

a) Just because men form an integral part of the systems, man's proneness to inaccuracy and the fact that not all men are honest under all circumstances, require an independent check on the system. „Independent" in this sense that the person who executes this check should have no personal interest in the outcome of the information system and be unallied to the persons whose accuracy and honesty are to be verified.

b) Even if a total information system provides top management with all relevant information accurately and timely there is no certainty that external financial statements prepared by, or on the order of, top management reflect truly all information they should contain. Determining that this is so requires expert knowledge (of an auditor) and independence in a wider sense. The person to verify external financial statements should be independent in the same sense as mentioned under (a), but, in addition to that, he should be independent from top management as well. This means: he should be in the public profession.

In many cases the need for internal audit of the information system and the need for external audit can be efficiently fulfilled by the same public accountant. In other cases it is more efficient to employ an internal auditor for the one requirement and a public accountant for the other; they should co-operate in such a manner that duplication of work is avoided as far as possible.

Summarizing: even in the application of a well-balanced and fully tested information system top management requires an independent opinion on the adequate operation and adaptation of the system, and the general public requires an independent opinion on the fairness of the external financial statements.

\subsection{The auditor's approach}

There will be hardly any similarity between the audit of financial statements based on fully manual or manual-automated accounting as we know it today, and the audit of total information systems.

In the latter case, test-checking of a time-period as a whole will not be feasible; test-checking of a number of single, unconnected items will not serve a useful purpose; there seems to be no sense in comprehensive working-papers in which accounts are analysed or reconciled, because the system already provides for any analysis or reconciliation that is wanted.

Adaptation of the auditor's approach to the system's characteristics can only 
be successful if the auditor is willing to master first of all the set-up of the system, then to use his critical judgment in ascertaining where things might go wrong, and finally to develop the means for checking the deviations before they have led to unwanted consequences.

Mastering the set-up of the system can be done in a variety of ways, which may be grouped into two broad categories:

a) Closely following the gradual development of the system, and giving advice on the elimination of weak spots which tend to creep into a system.

b) Analysing an already operating system.

Following the gradual development has the clear advantage of enabling the auditor to prevent mistakes and defects, but it is not applicable if the auditor is assigned a new account where a total information system is already in operation. Moreover, even if the auditor has been fully involved in the development and has approved each separate step, it is of ten useful to analyse the system as unimpaired by previous knowledge as is possible. In this way, particular aspects or elements which might have been overlooked in the development stage can be recognized.

This leads to the idea of team-work: some members of the auditor's firm are assigned to co-operate in the development of the system, others to analyse what has been set up.

Both groups need a thorough knowledge of ,information science", which includes the study of what information is or might be useful, as well as the knowledge of the ways and means along which gathering, processing, and providing of information can be implemented.

This, again, leads to the idea of team-work in another sense, because it cannot be expected that every single auditor will be an expert in all the different fields which form together ,information science”.

It is impossible to give specific rules for the manner in which the auditor should study an information system. Two pitfalls should be avoided:

1 The auditor's action should not go so far as setting up the system for management. This would jeopardize the auditor's independence [21], the sole reason for his existence (cf. section 7.1.).

It should be kept in mind that essentially the system is the management's system; management should bear full responsibility for it, either by using their own judgment or by entrusting the setup to someone other than the auditor.

2 The auditor should not iestrict himself to verifying the correctness of what is implemented in the system. He should be sufficiently specialized to be able to determine what is missing in the implementation, and he should use this expertise with adequate imagination.

The obvious way to start the analysis of an information system is to have the people who constructed the system explain it and show where and how certain features are implemented. This is an approach which differs fundamentally from the way in which biological or physical systems have to be analysed, where the response of the system is usually the only means of determining its properties. Information systems have been constructed per se by known human beings who can be, and should be, asked to explain what they did and why. 
Of course, the auditor should ascertain that the explanations he gets are truthful. He can do that by looking into the implementation (flowcharts; programs in programming languages; programs in machine-language; programs as stored in the machine) and by requiring demonstration (testdecks; reprocessing of parts). It should be kept in mind that, once the systems designers know that the auditor will verify now and then the truthfulness of their statements with regard to critical elements, they will realize that insincere answers might be exposed, by wich they would be characterized as being fraudulent. This would mean that the auditor, as long as he asks sensible and to-the-point questions, might generally expect to get honest answers.

In ascertaining where things might go wrong the auditor will usually find that full attention of the systems designers has been focussed on step-by-step correctness: each input item is checked within the system; each transfer of data within the system is checked; and often each output item is checked again. In most cases these checks are arrived at by some form of redundancy: either the data contains more bits than are necessary for the processing as such and the extra bits have a defined relation to the information bits, or the processing is duplicated and the two results are compared.

It is a wide-spread misconception that step-by-step checking can lead to overall correctness. There are 3 reasons why this is not so:

a) In general, step-by-step checking cannot ensure completeness. Omission of either input, processing, or output cannot be detected by step-by-step checking, unless a complete list exists of what input, processing, or output is to comprise; but then again the completeness of this checklist itself has to be ascertained.

b) Experience shows that it is well-nigh impossible to design a system of stepby-step checking that really covers all possibilities. Every now and then a combination of circumstances occurs for which no checks appear to have been implemented. Moreover all redundancy checks only give a relative safeguard against undetected errors. Even if the theoretical chance of an undetected error of a certain type is one in several millions of millions, there remains a possiblity that this error occurs in the very first item that is dealt with.

c) Step-by-step checking requires the isolated correction of each error detected. Sometimes this is an automatic correction which itself is checked in the same way. But in other cases the correction is to be made by human interference, of ten without any check on the way the error is corrected. If the „error" detected is no more than the overstepping of a limit check (or plausibility check), the acceptance or rejection of an item fully depends on human judgment.

For these reasons the auditor should look for, and, if need be, require to have introduced into the system, over-all checks, together with control fields which cover such a range that any difference can be located within a reasonable time. The types of over-all checks which are applicable vary from system to system. There is one main theme which is useful in the analysis of over-all checks; that is the concept of „consistency”. The system should provide for measures to check continuously that all interconnected records carry information (e.g. balances) which is consistent with the information of other records (cf. section 2.3.). The old idea of double-entry balancing should not be forgotten in this context, but it is certainly not the only or even the most important consistency to be verified. 
In total information systems consistency checks can often be executed automatically. It appears to be one of the main tasks and responsibilities of the auditor to advise about the introduction of this type of automatic check, wherever this is practicable. Even in the most automated information systems not all consistency checks can be automated. Here the auditor will have to form an opinion on the consistency himself, which in fact is not different from what is expected from him in a conventional audit.

Checking any deviations before they have had unwanted consequences involves that the auditor uses computer output, especially exception reports. This implies that he has to make sure that all computer output which is relevant for his opinion comes to his knowledge, which in itself will require him to visit the installation regularly and then perform a number of well-planned, but continually changing tests.

\subsection{Consequences for professional education}

It would require an extensive study to elaborate the consequences of the new techniques for the education for the profession. Only a few main outlines can be given here.

First, the knowledge of the use of automatic data processing in business and government should be part of the syllabus of every accountancy course. This would not deal with technicalities, but with the way in which A.D.P. can be efficiently used under various circumstances.

Secondly, new management techniques should be introduced into accountancy courses. As it seems impossible to make each accountant thoroughly acquainted with each subject in which the auditor should be an expert, some form of specialization seems unavoidable. Auditing, and the immediately related subjects (business economics, law, tax-law, accounting, professional ethics), should form part of the curriculum of all accountants; some freedom of choice from amongst additional subjects (advanced A.D.P., mathematical techniques, organizational matters, tax-expertise) should be possible.

Selecting the teachers for the new subjects might be a problem not too easily soluble. If experts in each field are chosen, special precautions are necessary to ensure that these experts will restrict themselves to that part of their field which is useful for auditors and not indulge in the subtleties of their profession. The ideal would be if a sufficient number of public accountants, each specialized in a particular field, were available for teaching.

Accountants who have qualified under the former rules will experience the need for application courses. The problem here seems to be much less severe, because application to changing circumstances has always been one of the characteristics of the accountant's profession. Still, the speed with which the new techniques are finding their way into business is much greater than in the past (Hollerith's punched card machines were first used in the 1880's; the first electronic computer was operational in 1946; the first business application of a computer only dates from 1952). Consequently, the need for systematic application is much greater than it used to be, and accountant's organizations will have to provide for application courses to their members. 
1 A. B. Frielink. „Auditing automatic data processing”. Elsevier, Amsterdam etc., 1961. German translation: - Buch - und Wirtschaftsprüfung bei elektronischer Datenverarbeitung. R. Oldenbourg. München und Wien, 1963. Danish translation (mimeographed) - Revision af ADB. Foreningen af Statsautoriserede Revisorer, 1962.

2 Joseph Pelej. „, How will business electronics affect the auditor's work?”. (The Journal of Accountancy [The American Institute of Accountants] 98, No. 1, July 1954, p. 36).

3 Wayne S. Boutell. „Auditing with the computer”. University of California Press, Berkeley and Los Angeles, 1965.

4 J. W. van Belkum \& A. J. van 't Klooster. „Administratieve automatisering en controle". Samsom, Alphen aan den Rijn, 1964.

5 Computer Research Studies, prepared by the System Development Corporation for the American Institute of C.P.A.'s New York, 1966: No. 1 Computer survey results; Voluntary comments; No. 2 Current basic sources of ADP information; No. 3 Computer applications to accounting operations; No. 4 Relationships among CPA's, banks and service bureaus; No. 5 Software trends; Hardware characteristics.

6 Y. Bar-Hillel. „An examination of information theory”. (Philosophy of Science, $22: 86-105$ ).

7 J. F. Schuh. ,Algemene theorie der automaten”. Centrex Eindhoven, 1963, p. 9 (Also in an English edition: General theory of automata).

8 R. G. Canning. „Installing electronic data processing systems”. Wiley, New York, 1957, p. 81.

9 M. C. Vaes. „Le contrôle interne dans l'entreprise”. Paris, 1964.

10 A. M. McDonough. „Information economics and management services”. New York, etc. 1963.

$11 \mathrm{H}$. Theil. „Optimal decision rules for government and industries”. Amsterdam, 1964.

12 G. N. Stilian et. al. „PERT, a new management planning and control technique". New York, 1962.

13 R. Schlaifer. "Probability and statistics for business decisions". New York, 1959.

14 J. D. William. ,The compleat-strategyst”. New York, 1954.

15 IFIP-ICC Vocabulary of information processing. Amsterdam, 1966.

16 American Data Processing Inc. „Total systems”. Detroit, Mich. 1962.

17 Norman J. Lenhart \& Philip L. Defliese. „Montgomery's Auditing”. New York, 1957. Chapter 1.

18 Ibid. Chapter 24, page 537.

19 F. Clive de Paula. "The principles of auditing”. London, 1966, page 348.

20 Howard Thompson. ,Joint man/machine decisions. The phase beyond data processing and operations research". Cleveland, Ohio, 1965.

21 R. Schattke and A. Smith. "Separation of management services and auditing desirable for independence". The Illinois C.P.A. Autumn 1965. 